\title{
Hubungan Antara Tinggi Tegakan, Biomasa Akar dan Jumlah Daun Semai Mangrove Avicennia marina
}

\section{Relation of Stand Height, Root Biomass and Number of Leaves of Mangrove Seedling of Avicennia marina}

\author{
Rini Budihastuti \\ Departemen Biologi, Fakultas Sains dan Matematika, Universitas Diponegoro \\ Jl. Prof. Soedarto, SH, Tembalang, Semarang \\ Email: rini_puryono@yahoo.com
}

Diterima 3 November 2016/Disetujui 29 Januari 2017

\begin{abstract}
ABSTRAK
Hubungan antar bagian tanaman pada tegakan semai mangrove dapat dimanfaatkan dalam upaya pendugaan pola pertumbuhan dan perubahan produktivitas tanaman. Penelitian ini bertujuan untuk mengetahui pertumbuhan bibit Avicennia marina yang disemaikan di wilayah pesisir semarang dan menganalisis hubungan antara tinggi tegakan, biomassa akar dan jumlah daun pada tegakan semai $A$. marina. Persemaian dilaksanakan selama 6 bulan terhadap bibit A. marina dengan polybag sebanyak 80 ulangan, sedangkan analisis data dilakukan dengan regresi. Hasil penelitian menunjukkan bahwa tingkat pertumbuhan semai $A$. marina sangat beragam dengan tinggi berkisar antara $17-68 \mathrm{~cm}$, jumlah daun $1-32$ helai dan biomasa akar 2,1 - 26,2 gr. Hasil analisis regresi menunjukkan bahwa ada pengaruh yang signifikan namun dengan koefisien determinasi yang rendah dari tinggi tegakan terhadap biomasa akar $\left(R^{2}=0,615\right)$, biomasa akar terhadap jumlah daun $\left(\mathrm{R}^{2}=0,330\right)$ dan tinggi tegakan terhadap jumlah daun $\left(\mathrm{R}^{2}=0,305\right)$. Hal ini dapat disimpulkan bahwa hubungan antar bagian semai mangrove $A$. marina pada usia 6 bulan masih relatif lemah.
\end{abstract}

Kata kunci: Avicennia marina, pertumbuhan, semai, hubungan antar bagian

\begin{abstract}
The relationship among plant partition on the stand of mangrove seedling can be utilized in the effort on the estimation of growth pattern and changes of plant productivity. This research aimed to know the growth of Avicennia marina seeded in the in the coastal area of Semarang city and to analyze the relation of stand height, root biomass and leaf abundance of A. marina seedling. Seeding was conducted for 6 months to A. marina seed in the polybags including 80 replication, while data analysis was conducted with regression. The result showed that the growth of A. marina seedling were varied including height range of $17-68 \mathrm{~cm}$, leaf abundance of $1-32$ sheets and root biomass of $2.1-26.2$ gr. Regression analysis showed there were significant relations among seedling partitions eventhough the determination coefficients were low, including the influence of stand height on the root biomass $(\mathrm{R} 2=0.615)$, root biomass on leaf abundance $(\mathrm{R} 2=0.330)$ and stand height on the leaf abundance $(\mathrm{R} 2=0.305)$. It is concluded that the relations among seedling partition of mangrove A. marina at the age of 6 months were relatively low.
\end{abstract}

Keywords: Avicennia marina, growth, seedling, among partitions relationship

\section{PENDAHULUAN}

Ekosistem mangrove merupakan penyedia jasa-jasa lingkungan dominan bagi wilayah pesisir dan juga pendukung perekonomian dan pangan bagi masyarakat pesisir (Friess, 2016). Mangrove memiliki struktur fisiologis yang unik sebagai bentuk adaptasi terhadap lingkungan pasang surut di wilayah pesisir. Habitat tumbuh mangrove yang berada di wilayah pesisir menyebabkan vegetasi tersebut rentan terhadap gangguan lingkungan. Kondisi lingkungan yang secara aktif berubah merupakan salah satu tekanan lingkungan yang 
dialami oleh tegakan mangrove. Jayatissa et al. (2008) menyatakan bahwa mangrove dapat mengalami perbedaan laju tumbuh akibat adanya tekanan lingkungan.

Avicennia marina merupakan jenis mangrove yang memiliki distribusi yang luas karena kemampuan adaptasinya yang baik (Wang'ondu et al., 2010). Avicennia marina merupakan jenis mangrove yang relatif rentan terhadap variasi kondisi lingkungan di wilayah pesisir. Penelitian Rasheed et al. (2013) dan Nguyen et al. (2015) menunjukkan bahwa tingkat pertumbuhan $A$. marina bervariasi terhadap kondisi lingkungan tumbuhnya.

Organ-organ pada tegakan tanaman pada umumnya memiliki fungsinya masing-masing yang berperan dalam pertumbuhan tanaman. Distribusi berbagai unsur-unsur nutrien antara akar dan daun tentunya melalui organ-organ lain seperti batang dan cabang sehingga tentunya tegakan tanaman mengalami adaptasi untuk memenuhi kapasitas tukar yang dibutuhkan (Delagrange et al., 2008). Keselarasan fungsi dari masing-masing organ tersebut secara tidak langsung berakibat pada keselarasan pola tumbuh antar organ tanaman (Bastien-Henri et al., 2010).

Adanya pertumbuhan tegakan tanaman berakibat pada perubahan organ-organ tanaman baik terhadap ukuran maupun biomasanya (SaintAndre et al., 2005). Hal ini berdampak pada perubahan produktivitas tanaman. Menurut Solari dan DeJong (2006), tekanan pada akar berpengaruh terhadap kandungan air daun dan laju transpirasi pohon, sehingga mempengaruhi tingkat pertumbuhan tegakan tanaman. Komiyama et al. (2008) menyatakan bahwa tingkat pertumbuhan tegakan mangrove merupakan salah satu faktor yang menentukan tingkat produktivitas mangrove dan fungsinya bagi lingkungan.

Domec et al. (2009) menunjukan bahwa organ-organ tanaman saling berkaitan satu dengan yang lain. Ketika salah satu bagian tanaman mengalami ganguan, maka seluruh fungsi tanaman juga akan tergangu. Borkar et al. (2011) menunjukkan bahwa perbedaan salinitas mempengaruhi tinggi tegakan semai mangrove. Menurut Tausch (2009), kondisi suatu bagian tegakan tanaman dapat digunakan untuk memperkirakan kondisi bagian yang lain. Hal tersebut umumnya dimanfaatkan untuk mengetahui kualitas tegakan tanaman khususnya pada tanaman-tanamn produksi. Lebih lanjut Chiraz (2013) menunjukan bahwa terdapat hubungan yang erat antara tinggi tegakan, diameter batang, cakupan akar dan diameter kanopi. Ukuran tegakan juga menentukan biomassa tanaman baik yang berada diatas permukaa tanah (batang, daun) maupun yang berada dibawah permukaan tanah (akar) (Komiyama et al. 2008). Dengan demikian, perkiraan terhadap biomasa mangrove dapat dilakukan berdasarkan pengukuran fisiknya semisal diameter tegakan.

Kondisi tanaman pada umumya bervariasi berdasarkan kondisi lingkungannya (Schafer dan Mack, 2014). Berbagai informasi mengenai karakteristik tanaman baik berupa tinggi tegakan, biomasa hingga produktivitasnya penting untuk diketahui khususnya terhadap tanaman-tanaman produksi.

Namun, untuk mengetahui kualitas tanaman yang dihasilkan tidak mungkin dilakukan pengambilan sampel terhadap tanaman, sehingga diperlukan metode pendugaan mengenai kondisi tanaman yang bersangkutan. Penelitian ini bertujuan untuk mengetahui bagaimana kondisi tegakan semai A. marina yang dibibitkan di wilayah pesisir semarang dan menganalisis hubungan antara tinggi tegakan, biomasa akar dan jumlah daun pada semai mangrove A. marina.

\section{METODE PENELITIAN}

Penelitian dilaksanakan di wilayah pesisir Kecamatan Tugu, Kota Semarang selama 6 bulan dari Mei - Oktober 2012. Obyek penelitian berupa semai Avicennia marina yang diperoleh dari kawasan mangrove di Kecamatan Tugu. Uji coba dilakukan dengan penanaman bibit A. marina dari biji/buah pada polibag yang telah diisi substrat. Jumlah sampel yang digunakan dalam penelitian ini sebanyak 80 tegakan.

Pengamatan dilakukan terhadap beberapa parameter tegakan yang meliputi jumlah daun, tingi tegakan dan biomasa akar. Analisis data dilakukan dengan regresi antar parameter dengan taraf kepercayaan $95 \%$. 


\section{HASIL DAN PEMBAHASAN}

Hasil penelitian menunjukkan bahwa tingkat kesuburan tegakan semai A. marina sangat beragam. Terdapat rentang yang signifikan dari jumlah daun, tinggi tegakan dan biomasa akar yang teramati. Tabel 1 menunjukkan kondisi tegakan semai A. marina yang disemaikan selama penelitian. Tabel 1 menunjukkan bahwa kondisi tegakan semai A. marina yang disemaikan sangat beragam. Berdasarkan kisaran dan rata-rata dari setiap variabel yang diamati, nampak bahwa distribusi data cenderung didominasi oleh nilainilai yang rendah. Hal ini menunjukkan bahwa tingkat pertumbuhan mangrove A. marina yang disemaikan relatif rendah.

Silambarasan dan Natarajan (2014) menyatakan bahwa variasi kandungan garam mempengaruhi pertumbuhan tajuk dan akar tanaman. Respons fisiologis mangrove juga ditunjukkan dengan adanya perbedaan jumlah daun dan luas daun. Bahkan, pengayaan nutrien secara berlebihan juga berdampak pada peningkatan mortalitas tanaman (Lovelock et al., 2009; Mangora, 2016). Noor et al. (2015) menjelaskan bahwa perbedaan kondisi fisiologis vegetasi mangrove berhubungan erat dengan kondisi lingkungan tumbuhnya. Vegetasi yang mengalami tekanan secara otomatis menyesuaikan proses-proses organik tegakan mangrove, sehingga pertumbuhan menjadi terhambat.

Analisis terhadap hubungan antar bagian tanaman menunjukkan adanya interaksi yang signifikan. Berdasarkan hasil uji regresi, nampak bahwa terdapat hubungan matematis antara jumlah daun, tinggi tegakan dan biomasa akar. Hubungan antar variabel pengamatan tersebut secara rinci disajikan pada Tabel 2.

Tabel 1. Kondisi tegakan semai mangrove A. marina

\begin{tabular}{lcc}
\hline \multicolumn{1}{c}{ Parameter } & Min - Maks & Rerata \pm StDev \\
\hline Jumlah Daun (helai) & $1-32$ & $10 \pm 6$ \\
Tinggi Tegakan $(\mathrm{cm})$ & $17-68$ & $37 \pm 11$ \\
Biomassa Akar $(\mathrm{gr})$ & $2,1-26,2$ & $10,7 \pm 5,6$ \\
\hline
\end{tabular}

Tabel 2. Hubungan antar bagian tegakan semai A. Marina

\begin{tabular}{lll}
\hline \multicolumn{1}{c}{ Parameter } & \multicolumn{1}{c}{ Persamaan } & \multicolumn{1}{c}{$\mathrm{R}^{2}$ (Sig.) } \\
\hline Tinggi Tegakan $\rightarrow$ Biomassa Akar & $\mathrm{E}^{\wedge}[-1,248+1,435 . \log (\mathrm{X})]$ & $0,615\{0,000)$ \\
Biomassa Akar $\rightarrow$ Jumlah Daun & {$[1,046+2,112 \cdot \log (\mathrm{X})]^{2}$} & $0,330(0,000)$ \\
Tinggi Tegakan $\rightarrow$ Jumlah Daun & {$[-2,664+3,714 \cdot \log (\mathrm{X})]^{2}$} & $0,305(0,000)$ \\
\hline
\end{tabular}

Tabel 2 menunjukkan bahwa determinasi dari variabel-variabel bebas yang diamati relatif rendah meskipun pengaruh yang dihasilkan bersifat signifikan. Hasil tersebut menunjukkan bahwa pertumbuhan masing-masing organ tegakan semai selain dipengaruhi oleh variabel yang diamati juga dipengaruhi oleh faktor-faktor lain. Hasil analisis tersebut membuktikan bahwa kondisi suatu tegakan mangrove dapat diperkirakan berdasarkan kondisi organ yang nampak.

Adanya hubungan antar organ tanaman telah banyak diteliti berdasarkan berbagai aspek pengamatan antara lain oleh Tausch (2009) yang untuk menduga kondisi biomassa batang dan
Chiraz (2013) yang menghubungkan luas kanopi dengan cakupan akar. Informasi mengenai kondisi tegakan mangrove penting untuk diketahui dalam upaya pemantauan status ekosistem, namun hal tersebut tidak dapat dilakukan secara langsung karena dapat merusak tegakan tanaman (Ghasemi et al., 2016).

Biomasa akar merupakan salah satu komponen penting yang mempengaruhi performa pertumbuhan semai mangrove. Eshel dan Grunzweig (2012) menyatakan bahwa akar merupakan komponen penting dalam siklus karbon dalam ekosistem mangrove. Berbagai komponen tajuk mangrove berkaitan erat dengan biomasa akar. Penelitian yang dilakukan Fortier et al. 
(2015) menunjukkan bahwa diameter tegakan secara signifikan berhubungan dengan biomasa akar dengan determinasi berkisar antara 0,780,90. Marziliano et al. (2015) menguji model pendugaan biomasa akar berdasarkan berbagai parameter tegakan. Hasil pengujian menunjukkan bahwa pendugaan biomasa akar dengan parameter tinggi tegakan, lingar pangkal akar dan diameter tajuk secara simultan menghasilkan determinasi sebesar 0,73. Sementara hasil penelitian ini hanya menunjukkan tingkat determinasi sebesar 0,615. Hal ini menunjukkan bahwa pendugaan biomasa akar mangrove lebih baik dilakukan dengan diameter tegakan dibandingkan dengan tinggi tegakan.

Daun dalam tegakan tanaman memiliki peranan penting dalam produktivitas primer tanaman (Kairo et al., 2008). Pendugaan terhadap kondisi daun tanaman pada umumnya didasarkan pada biomassanya. Hal ini merupakan indikator bagi produktivitas tanaman terhadap serasah yang dihasilkan. Determinasi biomasa daun terhadap akar pada kelompok pohon angiospermae mencapai 97\% (Poorter et al., 2011). Biomasa daun sendiri dipengaruhi oleh berbagai faktor antara lain oleh kandungan nutrien, kandungan air, suhu dan salinitas.

Menurut Defrenet et al. (2016), pada tanaman terdapat sinkronisasi antara daun dan akar. Daun mengalami penyusutan permukaan pada saat musim kemarau seiring dengan penurunan biomasa serabut akar. Menurut Alongi (2008), perbandingan biomasa kering akar dan daun berdasarkan diameter batang bertolak belakang pada beberapa jenis mangrove. Prosentase biomasa daun cenderung menurun seiring bertambahnya diameter mangrove, sedangkan prosentase biomasa akar justru meningkat.

Penelitian Ghasemi et al. (2016) telah menunjukkan bahwa terdapat hubungan yang signifikan antara tinggi tegakan dengan berat kering daun yang dihasilkan. Pendugaan terhadap biomasa daun dapat dilakukan melalui pengukuran tinggi dan diameter tegakan mangrove (Medeiros dan Sampaio, 2008).

Meskipun hubungan antar organ tanaman dapat dianalisis, namun masih diperlukan penelitian lebih jauh mengenai hubungan tersebut. Hal ini dikarenakan perbandingan biomasa tanaman cenderung mengalami perubahan seiring dengan bertambahnya umur tegakan tanaman (Saint-Andre et al., 2005). Perubahan pola hubungan alometri tanaman mangrove juga berkaitan erat dengan kondisi lingkungan (Peters et al., 2014).

Hasil penelitian menunjukkan bahwa baik jumlah daun, tinggi tegakan maupun biomasa akar saling terkait satu dengan yang lain. Hal ini menunjukkan bahwa untuk mengetahui kondisi salah satu bagian tanaman dapat dilakukan melalui pendugaan berdasarkan bagian tanaman yang dapat diukur. Namun, pendugaan pada tegakan semai dengan usia 6 bulan belum relevan karena tingkat keeratan hubunganya masih rendah. Komiyama et al. (2008) menyatakan bahwa hubungan alometri tanaman umumnya digunakan dalam pendugaan produktivitas primer ekosistem.

Hubungan alometrik tanaman bervariasi berdasarkan jenis dan usia (ukuran) tanaman. Dengan demikian, pemanfaatan data-data alometrik tanaman untuk pendugaan produktivitas suatu ekosistem perlu mendasarkan pada jenis tegakan yang ada. Dengan diketahuinya tingkat produktivitas primer ekosistem memungkinkan upaya pengelolaan suatu ekosistem berjalan dengan lebih baik, terutama dalam upaya pemanfaatan daya dukungnya untuk berbagai kegiatan lain.

\section{KESIMPULAN}

Tinggi tegakan, biomasa akar dan jumlah daun pada semai mangrove A. marina pada usia 6 bulan memiliki kondisi yang beragam dan didominasi oleh tingkat pertumbuhan yang rendah. Terdapat hubungan yang signifikan antara tinggi tegakan, biomassa akar dan jumlah daun yang menunjukkan bahwa pertumbuhan antar bagian tegakan mangrove saling berkaitan, meskipun koefisien determinasinya relatif rendah.

\section{DAFTAR PUSTAKA}

Alongi, D.M. 2008. The Energetics of Mangrove Forests. Springer Science + Business Media B.V. Netherlands. 
Bastien-Henri, S., Park A., Ashton M. dan Messier C. 2010. Biomass Distribution Among Tropical Tree Species Grown Under Regional Climates. Forest Ecology and Management 260: $403-410$.

Borkar, M.U., Athalye R.P. dan Goldin Q. 2011. Salinity Induced Changes in the Leaf Anatomy of the Mangrove Avicennia marina Along the Anthropogenically Stressed Tropical Creek. Journal of Coastal Development 14(3): $191-201$.

Chiraz, M.-C. 2013. Growth of Young Olive Trees: Water Requirement in Relation to Canopy and Root Development. American Journal of Plant Sciences 4: 1316 - 1344.

Defrener, E., Roupsard O., Meersche K.V.d., Charbonnier F., Perez-Molino J.P., Khac E., Prieto I., Stokes A., Roumet C., Rapidel B., Filho E.d.M.V., Vargas V.J., Robelo D., Barquero A. dan Jourdan C. 2016. Root Biomass, Turnover and Net Primary Productivity of A Coffee Agroforestry System in Costa Rica: Effects of Soil Depth, Shade Trees, Distance to Row and Coffee Age. Annals of Botany: $1-19$.

Delagrange, S., Potvin C., Messier C. dan Coll L. 2008. Linking Multiple-Level Tree Traits with Biomass Accumulation in Native Tree Species Used for Reforestation in Panama. Trees 22: $337-349$.

Domec, J.-C., Noormets A., King J.S., Sun G., McNulty S.G.,Gavazzi M.J., Boggs J.L. dan Treasure E.A. 2009. Decoupling the Influence of Leaf and Root Hydraulic Conductances on Stomatal Conductance and Its Sensitivity to Vapour Pressure Deficit as Soil Dries in A Drained Lablolly Pine Plantation. Plant, Cell and Environment 32: $980-981$.

Eshel, A. dan Grunzweig J.M. 2012. Root-Shoot Allometry of Tropical Forest Trees Determined in A Large-Scale Aeroponic System. Annals of Botany 112:291 - 296.

Fortier, J., Truax B., Gagnon D. dan Lambert F. 2015. Plastic Allometry in Coarse Root Biomass of Mature Hybrid Poplar Plantations. Bioenerg. Res. 8: 1691.
Friess, D.A. 2016. Ecosystem Services and Disservices of Mangrove Forests: Insights from Historical Colonial Observations. Forests 7: 183

Ghasemi, A., Fallah A. dan Joibary S.S. 2016. Allometric Equations for Estimating Standing Biomass of Avicennia marina in Bushehr of Iran. Journal of the Faculty of Forestry Istanbul University 66(2): 691 697.

Jayatissa, L.P., Wickramasinghe W.A.A.D.I., Dahdouh-Guebas F. dan Huxham M. 2008. Interspecific Variations in Responses of Mangrove Seedlings to Two Contrasting Salinities. Internat. Rev. Hydrobiol. 93(6): $700-710$.

Kairo, J.G., Lang'at J.K.S., Dahdouh-Guebas F., Bosire J. dan Karachi M. 2008. Structural Development and Productivity of Replanted Mangrove Plantations in Kenya. Forest Ecology and Management 225: 2670 2677.

Komiyama, A., ong J.E. dan Poungparn S. 2008. Allometry, Biomass, and Productivity of Mangove Forests: A Review. Aquatic Botany 89: 128 - 137 .

Lovelock, C.E., Ball M.C., Martin K.C. dan Feller I.C. 2009. Nutrient Enrichment Increases Mortality of Mangroves. PLoS ONE 4(5): e5600

Mangora, M.M. 2016. Nutrient Enrichment and Salini Conditions Decreases Growth and Photosynthesis of the Mangrove Heritiera littoralis Dryand. Open Journal of Marine Science 6: 293 - 301.

Marziliano, P.A., Lafortezza R., Medicamento U., Larusso L., Giannico V., Golangelo G. dan Sanesi G. 2015. Estimating Belowground Biomass and Root/Shoot Ratio of Phillyrea latifolio L. In the Mediterranean Forest Landscapes. Annals of Forest Science 72(5): $585-593$

Medeiros, T.C.C. dan Sampaio E.V.S.B. 2008. Allometry of Aboveground Biomasses in Mangrove Species in Itamaraca, 
Pernambuco, Brazil. Wetlands Ecol. Manage. 16: 323 - 330.

Nguyen, H.T., Stanton D.E., Schmitz N., Farquhar G.D. dan Ball. M.C. 2015. Growth Responses of the Mangrove Avicennia marina to Salinity: Development and Function of Shoot Hydraulic Systems Require Saline Conditions. Annals of Botany: mcu257

Noor, T., Batool N., Mazhar R. dan Ilyas N. 2015. Effects of Siltation, Temperature and Salinity on Mangrove Plants. European Academic Research 2(11): 14172 - 14179.

Peters, R., Vovides A.G., Luna S., Gruters U. dan Berger U. 2014. Changes in Allometric Relations of Mangrove Trees Due to Resources Availability - A New Mechanistic Modelling Approach. Ecological Modelling 283: 53 - 61.

Poorter, H., Niklas K.J., Reich P.B., Oleksyn J., Poot P. dan Mommer L. 2011. Biomass Allocation to Leaves, Stems and Roots: Meta-Analysis of Interspecific Variation and Environmental Control. New Phytologist 193: $30-50$.

Rasheed, M.Z., Normaniza O. dan Rozainah M.Z. 2013. Physiological Responses of Avicennia marina var acutissima and Bruguiera parviflora Under Simulated Rise in Sea Level. Sains Malaysiana 42(8): 1059 1064.

Saint-Andre, L., M'Bou A.T., Mabiala A., Mouvondy W., Jourdan C., Roupsard O., Deleporte P., Hamel O. dan Nouvellon Y. 2005. Age-Related Equations for Aboveand Below-Ground Biomass of A Eucalyptus Hybrid in Congo. Forest Ecology and Management 205: 199 - 214.

Schafer, J.L. dan Mack M.C. 2014. Growth, Biomass, and Allometry of Resprouting Shrubs After Fire in Scrubby Flatwoods. Am. Midl. Nat. 172: 266 - 284.

Silambarasan, N. dan Natarajan S. 2014. Growth and Mineral Constituents' Variations in Halophytic Species Under Salinity. International Letters of Natural Sciences 10: $24-34$.
Solari, L.I., dan DeJong M. 2006. The Effect of Root Pressurization on Water Relations, Shoot Growth and Leaf Gas Exchange of Peach (Prunus persica) Trees on Rootstocks with Differing Growth otential and Hydraulic Conductance. Journal of Experimental Botany 57(9): 1981 - 1989.

Tausch, R.J. 2009. A Structurally Based Analytic Model for Estimation of Biomass and Fuel Loads of Woodland Trees. Natural Resource Modeling 22(4): 463 - 488.

Wang'ondu, V.W., Kairo J.G., Kinyamario J.I., Mwaura F.B., Bosire J.O., Dahdouh-Guebas F. dan Koedam N. 2010. Phenology of Avicennia marina (Forsk.) Vierh in A Disjunctly-Zoned Mangrove Stand in Kenya. Western Indian Ocean J. Mar. Sci. 9(2): $135-144$. 